\title{
A Framework for Infusing Critical Thinking into Chinese College EFL Learners' Argumentative Writing Process
}

\author{
Chunxia $\mathrm{Lu}^{1,2}$ \\ ${ }^{1}$ Assumption University, Thailand \\ ${ }^{2}$ Yancheng Teachers University, Jiangsu China \\ Correspondence: E-mail: classforyc@163.com.
}

Received: April 2, 2019

doi:10.5430/elr.v8n2p16

\begin{abstract}
Written argumentation, as a language skill and a cognitive skill as well, is not easy for EFL learners. In China, related studies found that college EFL learners are weak in written argumentation due to the deficiency of critical thinking. In order to enhance Chinese college EFL learners' argumentative writing ability, this paper reviewed the nature of argumentative writing, the relationship between critical thinking and argumentative writing and previous studies on effects of critical thinking instruction into argumentative writing, and then pointed out that it is reasonable to infuse critical thinking into argumentative writing process in Chinese EFL context. With teachers' feedback and students' reflection as the pedagogical tool, the author synthesized an instruction framework for infusing critical thinking skills into Chinese EFL learners' argumentative writing process hopefully to provide reference for further research and instruction.
\end{abstract}

Keywords: Critical thinking skills, argumentative writing process, Chinese College EFL learners

\section{Introduction}

Argumentation, which is defined as the coordination of evidence and theory to support or refute an explanatory conclusion (Suppe, 1998) is central for collegiate writing with its potential to develop knowledge, enhance understanding of knowledge and sharpen ideas. Along with increasing recognition of the significance of argumentation, Chinese EFL educators began to realize the value of argumentation in high education and show their concern to the development of argumentation instruction in the EFL field. It is revealed from their findings that Chinese college students' argumentative writing ability is always labelled as weakness in reasoning, analysing, and backing, especially weak in applying evidence to support or refute the claims.

In Chinese context, there is no denying that arguing in English is never easy. The ability of argumentation is not inborn and it should be acquired through practice, instruction and modelling. Furthermore, it will be more challenging for learners to argue in a foreign language. To the native writers, writing is an automatic process while during the process of writing in a foreign language, writing becomes conscious. For example, writers always have difficulties in selecting words and generating ideas for accuracy and appropriateness when they write in a foreign language. Besides, learners have to face cultural challenges. To Chinese language learners, argumentation is always considered to be an act of threat to a harmonious atmosphere. Thus, in most cases, they are not used to arguing with others. From the perspective of school instruction, through a look at the writing curriculum and textbooks developed for Chinese EFL learners, no particular training activities are developed for students to connect argumentative writing with high-order thinking skills, such as critical thinking. Under such circumstances and despite of the challenges, the author proposed to infuse critical thinking instruction into argumentative writing process hopefully to enhance Chinese EFL learners' argumentative writing ability.

\section{Argumentative Writing}

In nature, argumentative writing shares the general process of writing. An argumentative writer needs to be motivated to write, keep positive attitudes towards the writing process, have specific goals, and take the audience into consideration. A writer will process topics, linguistic knowledge, organize ideas in order to produce a coherent written text. The common features that underlie the writing process, like planning, text production and interpretation also apply to argumentative writing process. 
However, argumentative writing has its own characteristics. It is a communication task that calls upon sophisticated cognitive and linguistic abilities (Nippold, 2010). Before writing, writers will predict the needs of readers, anticipate counterarguments and the questioning of their own claims. While writing, the writers are demanded to take a position to convince the readers to perform an action or to adopt a point of view. Since each argumentative essay argues for or against a certain claim in order to convince the audience, the writers always first identify his or her own topic and then decide which side to support and then offer facts, reasons or evidence to validate and justify their arguments to refute the counterarguments. During the whole process of argumentation, a calm and neutral tone is necessary in order to come to a convincing conclusion. A claim as the starting point, different sides of argumentation, and evidence with claims, backing, rebuttal and conclusions compromise the key elements of argumentative writings. Figure 2.1 illustrate the details of the process.

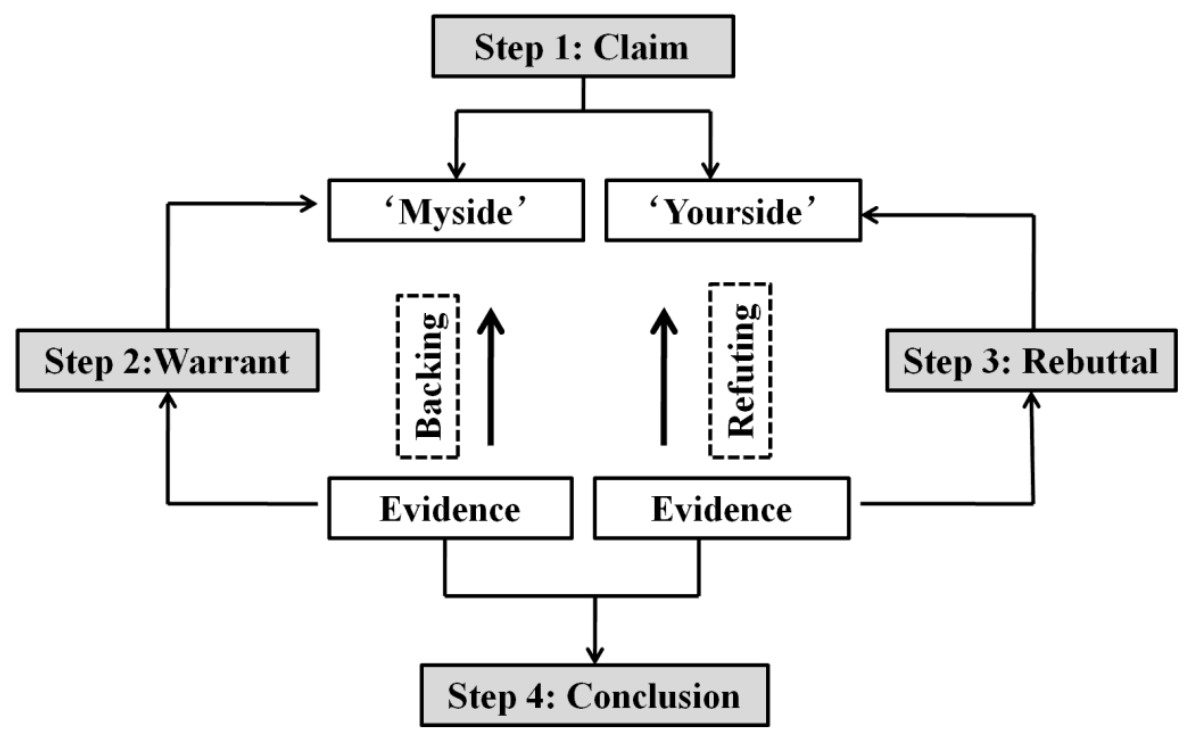

Figure 2.1: Argumentative Writing Process

\section{Potential of Infusing Critical Thinking into Argumentative Writing Process}

Critical thinking, which is rooted in western cultures, is defined variously. To Facione (1990), critical thinking is a purposeful, self-regulatory judgment which results in interpretation, analysis, evaluation, and inference, as well as explanation of the evidential, conceptual, methodological, criteriological, or contextual considerations upon which that judgment is based. Accordingly, critical thinking skills include integration, analysis, inference, explanation, evaluation, and self-regulation. Facione's definition on critical thinking is applied in this paper as it is thoroughly discussed and well documented, which has been tested by the time.

Critical thinking is naturally intertwined with argumentative writing as thinking and writing are always compatible, synergistic processes (Schmidt, 1999). When the students learn to write argumentatively, they also learn how to think critically at the same time. The process of argumentative writing will help formulate, clarify, expand, and deepen thinking in a critical way. To be specific, at the beginning stage of composing an argumentative essay, the writers need to comprehend the statement, express the meaning of the statement and evaluate whether it is controversial or not in order to come out an appropriate argument.

Later, writers have to distinguish the author's side from the alternative side, so that writers can gather evidence or data to support the writers' own side and argue against the opposite standpoints. Here, writers must evaluate the credibility and appropriateness of the evidence. Then the writers explain and justify why the evidence is collected and how it can back up the arguments or refute the counterarguments.

Finally in order to move to a convincing conclusion, writers need the ability to infer. The author will check the soundness of reasoning carefully and thoroughly to educe reasonable and convincing consequences. Self-regulation which requires the writers examine their own writing and thinking process will go through the whole writing process.

In brief, such skills as interpretation, analysis, self-regulation, and inference which are all termed as critical thinking skills are all involved in individuals' argumentative writing process. Thus, to be a successful argumentative essay writer, he should be equipped with critical thinking skills. 


\section{Effects of Critical Thinking in EFL Writing}

Theoretically, argumentative writing is closely related to critical thinking, but the relationship between the two in EFL writing practice is not definite. Gorjian, Pazhakh and Parang (2012) reported that the instruction of critical thinking is pedagogically effective to enhance Iranian EFL students' writing skills among both male and female students. However, Mansoor (2012) also invested the effect of critical thinking on developing argumentative essays by Iranian EFL college students based on the theory of reflective language teaching and critical pedagogy. It was reported that critical thinking instruction can help the students to think more critically but it can't develop argumentative writing ability.

Kolour and Yaghoubi (2015) studied the impact of teaching critical thinking tasks on coherence in argumentative essay writing among Iranian teenage EFL learners. The study focused on the instruction of two critical thinking tasks: Identify-Cause-and-Effect-Relation tasks and Divergent-thinking tasks. 70 junior sixteen-year-old students with relative the same level of EFL proficiency were divided into two separate groups of 35 through convenience sampling as the participant of the study. Persian version of critical thinking questionnaire, two proficiency tests of IELTS, Identify-Cause-and-Effect-Relation tasks and Divergent-thinking tasks were employed to collect data. After quantitative data analysis, participants in both groups make significant progress before and after the treatment, while the difference between the improvements for both tasks was negligible, which implies that both given critical thinking tasks can motivate EFL learners to be better and competent argumentative writers in terms of coherency in argumentative essays.

Nevertheless, Mehta \& Almahrooqi (2015) investigated whether thinking can be educated in EFL context via connecting critical thinking and writing in classrooms. This research grounded itself on a qualitative case study of college-level English majors and explored the approach to instruct critical thinking in EFL contexts. The findings reported that critical thinking is helpful for the development of argumentative writing ability and meanwhile suggest that critical thinking will work well when it is best characterized as a series of skills which can be consistently worked upon by students. This skill is further enhanced when students get a chance to compose on the areas which have been discussed in the class, especially if they are of some relevance to the students' own unique circumstances.

Pei, Zheng, Zhang and Liu (2017) invested the association between critical thinking skills and EFL argumentative writing among Chinese undergraduates. The study examined 1) critical thinking ability among English majors in Chinese universities and differences across grades, 2) the relationship between English majors' critical thinking ability and their EFL argumentative writing performance and 3) critical thinking ability exhibited in their EFL writings. It was found that there was no significant correlation between EFL argumentative writing performance and critical thinking skills among Chinese college EFL learners. However, through textual analysis of typical essays, EFL learners with high level of critical thinking skills outperformed those with lower level in terms of relevance, clarity, logicality, profundity and flexibility of argumentative writing. Pedagogically it was suggested to integrate critical thinking into EFL writing instruction.

To summarize, it can be inferred that critical thinking is closely related to argumentative writing ability and pedagogically critical thinking will help argumentative writing but how and what effect critical thinking play a role in argumentative writing process is not definite and needs further research. It can be implied form the studies above that it is possible to instruct critical thinking in Chinese argumentative writing classes but the instruction models should be well designed depending on different contexts.

\section{The Design of a Framework for Infusion}

In terms of critical thinking instruction, Ennis (1989) put forward four approaches for training critical thinking skills: general, infusion, immersion, and a mixed instruction approach. Among the four approaches, the infusion approach (also called the embedded approach) refers to explicitly teaching critical thinking skills within a specific discipline. Abrami (2008) figured out that "the improvement of students' critical thinking can never be a matter of implicit expectation...Educators must take steps to make critical thinking objectives explicit in courses..." Through explicit introduction of critical thinking, learners can reflect on what ways of doing are good for them to practice and what plans are the best ones for them to adopt in doing similar kinds of thinking. They will build the habit of doing specific types of thinking, and familiarize themselves with occasions on which critical thinking calls for. In a word, the more explicit the teaching of critical thinking is, the greater impact it will make on students (Swartz, 2001). Accordingly, critical thinking will be explicitly instructed into Chinese argumentative writing courses. In order to maximize the effects of infusion, teachers' feedback and students' reflection are integrated into the infusion process to facilitate explicit instruction. 


\subsection{Teachers' Feedback}

Any teachers' response to students' writing in order to promote better writing can be defined as feedback. Teachers' feedback can be done in an oral or written way, while the written feedback is the method which is the most often used in delivering teachers' response to a piece of writing. Students at college level prefer to receive direct and explicit feedback which can clearly guide them how to revise the text (Bitchener, 2008). Teachers are also suggested to follow a format to make comments for better feedback. Teachers' feedback will help develop students to be independent writers and promote their autonomous writing skills. Then, teachers' written feedback becomes a crucial part for mastery of written argumentation via infusion of critical thinking.

\subsection{Students'Reflection}

To Dewey, reflection is a purposeful thinking toward a goal and a mental route of internal problem solving activity (Dewey, 1933). Boud, Keogh and Walker (1985) defined reflection to be an individual practice to assess a particular experience from a new point for better performance. According to Black and Plowright, reflection is "the process of engaging with learning and/or professional practice that provides an opportunity to critically analyze and evaluate that learning or practice" (2010, p. 246). Thus, students' reflection is characterized by being active, exploratory and critical.

During the process of writing, reflection, which takes place when students draft, redraft and revise their written texts, deepen students' thinking beyond the surface level and help students to organize ideas into a more logical structure and thereby achieve deep understanding and meanwhile improve the written text.

Students' reflection is necessary and helpful for infusing critical thinking into writing process. With reflection, students rethink their current learning experience actively and critically and then explore the questions from a new and higher lever. Here students' reflection together with teachers' feedback serve as a helpful tool to promote the infusion process.

\subsection{The Framework for Infusion}

Combined with critical thinking skills and argumentative writing process, with the help of teachers' feedback and students' reflection as the pedagogical strategies, the framework for infusion is proposed (Figure 4.1), which will provide guidance to infuse critical thinking instruction into argumentative writing classes. Within the framework, argumentative writing elements infused by critical thinking skills will be explicitly instructed. Teachers' feedback will intentionally scaffold students' learning. Teachers' explicit explanation, teachers' feedback and students' reflection will serve as a self-report pedagogical tool in the instruction process.

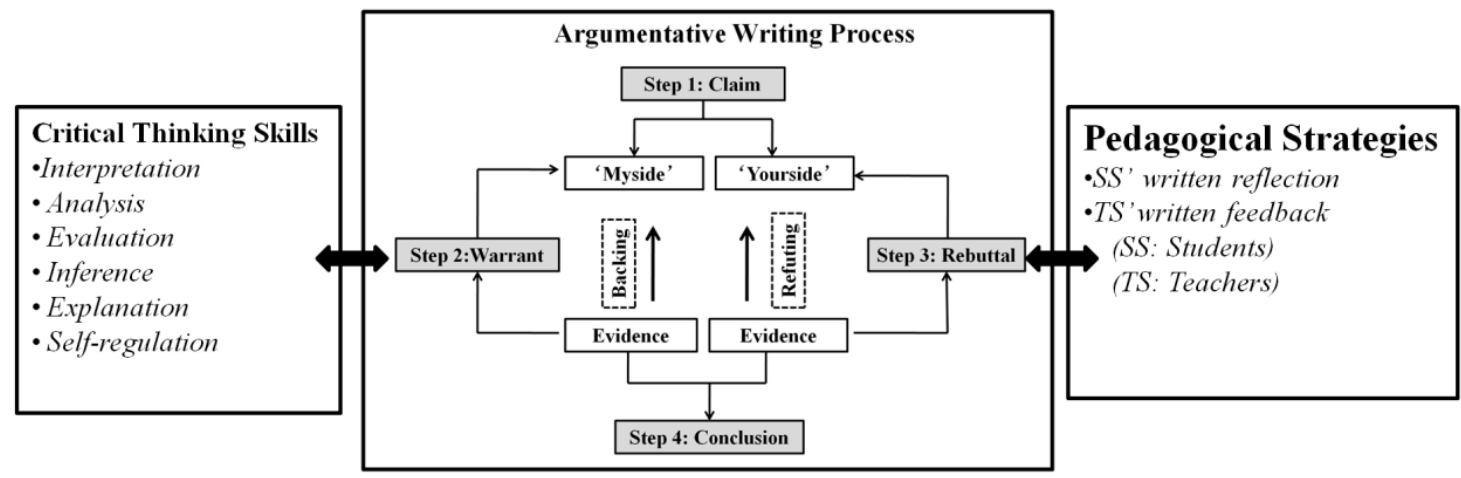

Figure 4.1: A Framework for Infusing Critical Thinking into Chinese EFL Argumentative Wiring Process

\section{Conclusions}

In this paper, argumentative writing, the relationship between argumentation and critical thinking and the effects of critical thinking in argumentation were discussed. So far then, the necessity and possibility of infusing critical thinking into argumentation process is obvious. Despite few negative reports about the effects of critical thinking into argumentation, a well written and organized piece of argumentative work will often be considered to be average if it does not include original and new critical ideas at a college level writing. Thus, it is reasonable and grounded to infuse critical thinking into Chinese argumentative writing classes. Then considering the nature of argumentative writing, critical thinking, and the role of teachers and students, a framework for infusing critical thinking skills into argumentative writing process is proposed as reference for further empirical study. Students' written reflection and 
teachers' written feedback are applied to facilitate the infusion prococess. Hopefully the framework for infusion can shed light into pedagogical practice in argumentative writing classes.

\section{References}

Abrami, P. C., Bernard, R. M., Borokhovski, E., Wade, A., Surkes, M. A., Tamim, R., \& Zhang, Dai. (2008). Instructional interventions affecting critical thinking skills and dispositions: A stage 1 meta-analysis. Review of Educational Research, 78(4), 1102-1134.

Bitchener J. (2008). Evidence in support of written corrective feedback. Journal of Second Language Writing, 17(2), $102-118$.

Black, P. E., \& Plowright, D. (2010). A multi-dimensional model of reflective learning for professional development. Reflective Practice: International and Multidisciplinary Perspectives, 11(2), 245-258. https://doi.org/10.1080/14623941003665810.

Boud, D., Keogh, R., \& Walker, D. (1985). Promoting reflection in learning: A model. In D. Boud, R. Keogh, \& D. Walker, Reflection: Turning experience into learning (pp. 18-40). London: Kogan Page.

Dewey, J. (1933). How we think: A restatement of the relation of reflective thinking to the educative process. Boston: Houghton Mifflin Company.

Ennis. R. H. (1991). Critical thinking: A streamlined conception. Retrieved from http://link.springer.com/chapter/10.1007/978-1-137-37805-7_2\#page-1.

Facione, P. A. (1990). Critical thinking: A statement of expert consensus for purposes of educational assessment and instruction. Research findings and recommendations. American Philosophical Association, Newark, DE. (ERIC Document Reproduction Service No. ED 315423)

Gorjian, B., Pazhakh, A., \& Parang, K. (2012). An investigation on the effect of critical thinking (CT) instructions on Iranian EFL Learners' descriptive writing: A case of gender study. Advances in Asian Social Science, 1(1), 114-118.

Kolour, D. M., \& Yaghoubi, A. (2015) The Impact of Teaching Critical Thinking Tasks on Coherence in Argumentative Writing among EFL Learners. Mediterranean Journal of Social Science, 460-467.

Mansoor, F. (2012). The effect of critical thinking on developing argumentative essay by Iranian EFL university students. Journal of Language Teaching and Research, 3(4), 632-628.

Mehta, S. R., \& Almahrooqi, R. (2015). Can thinking be taught? Linking critical thinking and writing in an EFL context. RELC Journal, 46(1), 23-36.

Nippold, M. A., Wardlonergan, J. M., \& Fanning, J. L. (2005). Persuasive writing in children, adolescents, and adults: a study of syntactic, semantic, and pragmatic development. Language Speech \& Hearing Services in Schools, $36(2), 125$.

Pei, Z., Zheng, C., Zhang, M., \& Liu, F. (2017). Critical thinking and argumentative writing: inspecting the association among EFL learners in China. English Language Teaching, 10(10), 31.

Schmidt, J. S. (1999). Using Writing to Develop Critical Thinking Skills. NACTA Journal. December.

Suppe. (1998). the Structure of a Scientific Paper. Philosophy of Science, 65(3), 381-405.

Swartz, R. (2001). Infusing the Teaching of Critical and Creative Thinking into Content Instruction, in Developing Minds, Association of Supervision and Curriculum Development, Alexandria, Virginia. 